\title{
The Janus-faced atracotoxins are specific blockers of invertebrate $\mathrm{K}_{\mathrm{Ca}}$ channels
}

\section{Simon J. Gunning ${ }^{1}$, Francesco J. Maggio ${ }^{2,4}$, Monique J. Windley ${ }^{1}$, Stella M. Valenzuela ${ }^{1}$, Glenn F. King ${ }^{3}$ and Graham M. Nicholson ${ }^{1}$}

1 Neurotoxin Research Group, Department of Medical \& Molecular Biosciences, University of Technology, Sydney, Broadway, NSW 2007, Australia

2 Department of Molecular, Microbial \& Structural Biology, University of Connecticut School of Medicine, Farmington, Connecticut 06032, USA and

3 Division of Chemical and Structural Biology, Institute for Molecular Bioscience, University of Queensland, Brisbane QLD 4072, Australia

4 Current affiliation: Bristol-Myers Squibb, 6000 Thompson Road, Syracuse NY 13057, USA

Subdivision: Molecular Neurobiology

Abbreviations: ACTX, atracotoxin; 4-AP, 4-aminopyridine; $\mathrm{BK}_{\mathrm{Ca}}$ channel, large-conductance $\mathrm{Ca}^{2+}$-activated $\mathrm{K}^{+}$channel; $\mathrm{Ca} v$ channel, voltage-activated $\mathrm{Ca}^{2+}$ channel; ChTx, charybdotoxin; DRG, dorsal root ganglia; DUM, dorsal unpaired median; EGTA, ethylene glycol-bis(b-aminoethyl ether)- $N, N, N^{\prime} N^{\prime}$-tetraacetic acid; IbTx, iberiotoxin; J-ACTX, Janus-faced atracotoxin; $\mathrm{K}_{\mathrm{A}}$ channel, transient 'A-type' $\mathrm{K}^{+}$channel; $\mathrm{K}_{\mathrm{Ca}}$ channel, $\mathrm{Ca}^{2+}$-activated $\mathrm{K}^{+}$channel; $\mathrm{K}_{\mathrm{DR}}$ channel, delayed-rectifier $\mathrm{K}^{+}$channel; $\mathrm{K}_{\mathrm{V}}$ channel, voltage-activated $\mathrm{K}^{+}$channel; $\mathrm{Na}_{\vee}$ channel, voltage-activated $\mathrm{Na}^{+}$channel; Slo, Slowpoke; TEA, tetraethylammonium; TTX, tetrodotoxin.

RUNNING TITLE: Janus-faced atracotoxins block $\mathrm{K}_{\mathrm{Ca}}$ channels

ADDRESS CORRESPONDENCE TO: Graham M. Nicholson, Department of Medical \& Molecular Biosciences, University of Technology, Sydney, PO Box 123, Broadway NSW 2007, Australia. Tel: +61 2 9514-2230 Fax: +61 2 9514-2228; E-mail: Graham.Nicholson@uts.edu.au 


\section{ABSTRACT}

The Janus-faced atracotoxins are a unique family of excitatory peptide toxins that contain a rare vicinal disulfide bridge. Although lethal to a wide range of invertebrates, their molecular target has remained enigmatic for almost a decade. We demonstrate here that these toxins are selective, high-affinity blockers of invertebrate calcium-activated $\mathrm{K}^{+}\left(\mathrm{K}_{\mathrm{Ca}}\right)$ channels. J-ACTX-Hv1c, the prototypic member of this toxin family, selectively blocked $\mathrm{K}_{\mathrm{Ca}}$ channels in cockroach unpaired dorsal median neurons with an $\mathrm{IC}_{50}$ of $2 \mathrm{nM}$, but it did not significantly affect a wide range of other voltage-activated potassium $\left(\mathrm{K}_{\mathrm{V}}\right)$, calcium $\left(\mathrm{Ca}_{\mathrm{V}}\right)$, or sodium $\left(\mathrm{Na}_{\mathrm{V}}\right)$ channel subtypes. J-ACTX-Hv1c blocked heterologously expressed cockroach $\mathrm{BK}_{\mathrm{Ca}}(p S l o)$ channels without a significant shift in the voltage-dependence of activation. However, the block was voltagedependent, indicating that the toxin likely acts as a pore blocker rather than a gating modifier. The molecular basis of the insect selectivity of J-ACTX-Hv1c was established by its failure to significantly inhibit mouse $m S l o$ currents $\left(\mathrm{IC}_{50} \sim 10 \mu \mathrm{M}\right.$ ) and its lack of activity on rat dorsal root ganglion neuron $I_{\mathrm{K}(\mathrm{Ca})}$. This study establishes the Janus-faced atracotoxins as valuable tools for the study of invertebrate $\mathrm{K}_{\mathrm{Ca}}$ channels and suggests that $\mathrm{K}_{\mathrm{Ca}}$ channels might be a potential insecticide target. 


\section{INTRODUCTION}

The Janus-faced atracotoxins (J-ACTXs) are a novel family of excitatory neurotoxins isolated from the venom of the deadly Australian funnel-web spider [1]. In addition to their unusual pharmacology, these peptide toxins are structurally unique: in addition to having an inhibitory cystine knot motif that is common to peptide toxins [2, 3], they contain a rare and functionally critical vicinal disulfide bridge between adjacent amino acid residues [1].

Although lethal to a wide range of invertebrates, including flies, crickets, mealworms, and budworms but inactive in mice, chickens and rats [1, 4-6], the molecular target of the J-ACTXs has remained elusive ever since their discovery. The insect-specificity and excitatory phenotype of J-ACTX-Hv1c are reminiscent of a subclass of scorpion $\beta$-toxins that target insect $\mathrm{Na}_{\mathrm{V}}$ channels [7]. In addition, the 3D structure of J-ACTX-Hv1c resembles that of the excitatory $\mathrm{Na}_{\mathrm{V}}$ channel modulator $\delta$-ACTX-Hv1a from the funnel-web spider Hadronyche versuta [8]. However, $\mathrm{Na}_{\mathrm{V}}$ channels cannot be the primary target of the J-ACTXs since they are active against the nematode Caenorhabditis elegans (G.F.K., unpublished data), which does not possess $\mathrm{Na}_{\mathrm{V}}$ channels [9].

In this study, we used patch clamp analysis of cockroach dorsal unpaired median (DUM) neurons to determine the molecular target of the Janus-faced atracotoxins. We demonstrate that J-ACTX-Hv1c is a high-affinity blocker of insect large-conductance $\mathrm{Ca}^{2+}$-activated $\mathrm{K}^{+}\left(\mathrm{BK}_{\mathrm{Ca}}\right)$ channel currents, whereas it has minimal effect on mouse or rat $\mathrm{BK}_{\mathrm{Ca}}$ channels. This work establishes the Janus-faced atracotoxins as valuable tools for the study of invertebrate $\mathrm{BK}_{\mathrm{Ca}}$ channels, and it indicates that insect $\mathrm{BK}_{\mathrm{Ca}}$ channels might be useful targets for development of novel insecticides. 


\section{RESULTS}

\section{Specificity of J-ACTX-Hv1c action}

Because of its structural homology to $\delta$-ACTX-Hv1a, the lethal toxin from Australian funnel-web spiders that delays inactivation of both vertebrate and invertebrate $\mathrm{Na}_{\mathrm{V}}$ channels $[8$, 10], we examined whether J-ACTX-Hv1c modulates $\mathrm{Na}_{\mathrm{v}}$ currents in cockroach DUM neuron. Test pulses to $-10 \mathrm{mV}$ elicited a fast activating and inactivating inward $I_{\mathrm{Na}}$ in DUM neurons that could be abolished by addition of $150 \mathrm{nM}$ TTX. Subsequent exposure of isolated $I_{\mathrm{Na}}$ to $1 \mu \mathrm{M} \mathrm{J}$ ACTX-Hv1c failed to alter peak current amplitude, inactivation kinetics (Figure 2A), or the voltage dependence of activation (data not shown, $n=5$ ). Subsequently, the actions of the toxin were assessed on global inward $I_{\mathrm{Ca}}$ in cockroach DUM neurons [11]. The elicited current was abolished by addition of $1 \mathrm{mM} \mathrm{CdCl} 2$, confirming that currents were carried via $\mathrm{Ca}_{\mathrm{v}}$ channels. Application of J-ACTX-Hv1c (1 $\mu \mathrm{M})$ failed to inhibit $I_{\mathrm{Ca}}$ elicited by a range of depolarizing test pulses from -80 to $+20 \mathrm{mV}$ (Figure $2 \mathrm{~B}, n=5$ ), or alter the voltage dependence of $\mathrm{Ca}_{\mathrm{v}}$ channel activation (data not shown, $n=5$ ). This indicates that J-ACTX-Hv1c does not affect invertebrate $\mathrm{Ca}_{V}$ channels.

\section{Effects of J-ACTX-Hv1c on $\mathrm{K}_{v}$ channel currents}

Macroscopic $I_{\mathrm{K}}$ in DUM neurons were recorded in isolation from $I_{\mathrm{Na}}$ and $I_{\mathrm{Ca}}$ by using $200 \mathrm{nM}$ TTX and $1 \mathrm{mM} \mathrm{Cd}^{2+}$, respectively. Macroscopic $I_{\mathrm{K}}$ were elicited by 100 -ms depolarizing pulses to $+40 \mathrm{mV}$ (Figure $2 \mathrm{~F}$ inset) before, and $10 \mathrm{~min}$ after, perfusion with toxin. In contrast to the lack of overt modulation of $\mathrm{Ca}_{\mathrm{v}}$ and $\mathrm{Na}_{\mathrm{V}}$ channels, $1 \mu \mathrm{M}$ J-ACTX-Hv1c inhibited macroscopic outward $I_{\mathrm{K}}$ by $56 \pm 7 \%(n=5$, Figure 2C). This block was not accompanied by a shift in the voltage-dependence of activation (data not shown). Block of macroscopic outward $I_{\mathrm{K}}$ indicates 
that J-ACTX-Hv1c targets at least one of the four distinct $\mathrm{K}^{+}$channel subtypes identified in DUM neuron somata [12]. These include delayed-rectifier $\left(K_{D R}\right)$, transient 'A-type' $\left(K_{A}\right), \mathrm{Na}^{+}$activated $\left(\mathrm{K}_{\mathrm{Na}}\right)$, as well as 'late-sustained' and 'fast-transient' $\mathrm{Ca}^{2+}$-activated $\left(\mathrm{K}_{\mathrm{Ca}}\right) \mathrm{K}^{+}$channels. The fast-transient $\mathrm{K}_{\mathrm{Ca}}$ channel differs from the late-sustained $\mathrm{K}_{\mathrm{Ca}}$ channel in that it inactivates rapidly after activation and displays a voltage-dependent resting inactivation [13]. As a consequence of the inhibition of total $I_{\mathrm{K}}$, all subtypes except $\mathrm{K}_{\mathrm{Na}}$ channels were investigated as potential targets of the Janus-faced atracotoxins.

In order to isolate $I_{\mathrm{K}(\mathrm{DR})}$ in DUM neurons, $I_{\mathrm{K}(\mathrm{A})}$ were blocked with $5 \mathrm{mM}$ 4-AP [13]. Additional experiments were required to determine the concentration of ChTx necessary to block $I_{\mathrm{K}(\mathrm{Ca})}$ in DUM neurons. Initial tests using $1 \mathrm{mM} \mathrm{CdCl}_{2}$ produced only $35 \pm 7 \%(n=7)$ inhibition of total outward $I_{\mathrm{K}}$ in the presence of $5 \mathrm{mM}$ 4-AP. Increasing concentrations of ChTx in the presence of $1 \mathrm{mM} \mathrm{CdCl} 2$ further inhibited total outward $I_{\mathrm{K}}$ in a concentration-dependent manner. Addition of ChTx revealed a steep dose-response relationship with inhibition of $I_{\mathrm{K}}$ to $46 \pm 5 \%$ at $30 \mathrm{nM}$ and $46 \pm 3 \%$ at $100 \mathrm{nM}(n=5)$ indicating maximal inhibition of $I_{\mathrm{K}(\mathrm{Ca})}$ at doses $\geq 30 \mathrm{nM}$ (Figure 2D, E). This indicated that inhibition of $\mathrm{Ca}^{2+}$ entry using $\mathrm{CdCl}_{2}$ alone was insufficient to block total $I_{\mathrm{K}(\mathrm{Ca})}$. Experiments requiring complete inhibition of $I_{\mathrm{K}(\mathrm{Ca})}$, such as those involving $I_{\mathrm{K}(\mathrm{DR})}$ and $I_{\mathrm{K}(\mathrm{A}) \text {, }}$ were therefore performed with both $1 \mathrm{mM} \mathrm{CdCl}_{2}$ and $30 \mathrm{nM}$ ChTx. Thus, outward $I_{\mathrm{K}(\mathrm{DR})}$ could be recorded in isolation from other $I_{\mathrm{K}}$ channel subtypes by the addition of $1 \mathrm{mM} \mathrm{CdCl}_{2}, 5 \mathrm{mM}$ AP and 30 nM ChTx. J-ACTX-Hv1c $(1 \mu \mathrm{M})$ did not inhibit $I_{\mathrm{K}(\mathrm{DR})}$ (Figure $\left.2 \mathrm{~F}, n=5\right)$, nor did it alter the voltage-dependence of activation ( $n=5$, data not shown).

Neither $I_{\mathrm{K}(\mathrm{A})}$ nor $I_{\mathrm{K}(\mathrm{Ca})}$ can be recorded in isolation from $I_{\mathrm{K}(\mathrm{DR})}$ as they are no selective blockers of 
insect $K_{\mathrm{DR}}$ channels [13]. Thus, $I_{\mathrm{K}(\mathrm{A})}$ were isolated using a prepulse current subtraction routine in the presence of $1 \mathrm{mM} \mathrm{CdCl} 2$ and $30 \mathrm{nM}$ ChTx to block $I_{\mathrm{K}(\mathrm{Ca})} \cdot I_{\mathrm{K}(\mathrm{DR})}$ were elicited in isolation from $I_{\mathrm{K}(\mathrm{A})}$ by inactivating $I_{\mathrm{K}(\mathrm{A})}$ using a one-second depolarizing prepulse to $-40 \mathrm{mV}$ followed by a 100 -ms test pulse to $+40 \mathrm{mV}$ (Figure 2G inset). Currents recorded under these conditions were digitally subtracted off-line from $I_{\mathrm{K}(\mathrm{DR})}$ and $I_{\mathrm{K}(\mathrm{A})}$ recorded with a prepulse potential to $-120 \mathrm{mV}$. This permitted isolation of $I_{\mathrm{K}(\mathrm{DR})}$ from $I_{\mathrm{K}(\mathrm{A}) \text {. }} \mathrm{J}-\mathrm{ACTX}-\mathrm{Hv} 1 \mathrm{c}(1 \mu \mathrm{M})$ produced a minor inhibition of $I_{\mathrm{K}(\mathrm{A})}$ by $14 \pm 4 \%(\mathrm{p}<0.05, n=5)$ elicited by depolarizing pulses to $+40 \mathrm{mV}$ (Figure $\left.2 \mathrm{~F}\right)$. Again, J-ACTX-Hv1c failed to alter the voltage dependence of activation (data not shown, $n=5$ ).

To record $I_{\mathrm{K}(\mathrm{Ca})}$ in isolation from other $\mathrm{K}_{\mathrm{V}}$ channel currents, a current-subtraction routine following perfusion with the $\mathrm{K}_{\mathrm{Ca}}$ channel blockers $\mathrm{CdCl}_{2}$ and $\mathrm{ChTx}$ was utilised. Control macroscopic $I_{\mathrm{K}(\mathrm{DR})}$ and $I_{\mathrm{K}(\mathrm{Ca})}$ were elicited in the presence of $5 \mathrm{mM}$ 4-AP to block $I_{\mathrm{K}(\mathrm{A}) \text {. }}$. J-ACTX-Hv1c was then perfused for a period of 10 min or until equilibrium was reached. $\mathrm{CdCl}_{2}$ $(1 \mathrm{mM})$ and ChTx $(30 \mathrm{nM})$ were then added to block $\mathrm{K}_{\mathrm{Ca}}$ channels. Residual $\mathrm{K}_{\mathrm{DR}}$ channel currents recorded in the presence of the $I_{\mathrm{K}(\mathrm{Ca})}$ blockers were then digitally subtracted from both controls and currents recorded in the presence of J-ACTX-Hv1c (see Fig. 2G) to isolate $I_{\mathrm{K}(\mathrm{Ca})}$. This subtraction routine is valid given the distinct lack of activity of J-ACTX-Hv1c on $I_{\mathrm{K}(\mathrm{DR})}$. Isolated $I_{\mathrm{K}(\mathrm{Ca})}$ exhibited fast activation, but inactivated in two phases. Initial inactivation resulted in a fast-transient component, with a subsequent late-maintained phase that displayed much slower inactivation kinetics. The $I_{\mathrm{K}(\mathrm{Ca})}$ also activated at membrane potentials greater than -50 $\mathrm{mV}$. These characteristics are classical of $\mathrm{BK}_{\mathrm{Ca}}$ currents recorded in DUM neurons [12, 13].

In contrast to the lack of overt actions on $\mathrm{K}_{\mathrm{DR}}$ and $\mathrm{K}_{\mathrm{A}}$ channels, J-ACTX-Hv1c produced a potent block of $I_{\mathrm{K}(\mathrm{Ca})}$ that was only partially reversible following prolonged washout in toxin-free 
solution (Fig. 3A). Inhibition of cockroach $I_{K(\mathrm{Ca})}$ was dose-dependent with $\mathrm{IC}_{50}$ values of $2.3 \mathrm{nM}$ and $2.9 \mathrm{nM}$, at $+40 \mathrm{mV}$, for the fast-transient and late-sustained $I_{\mathrm{K}(\mathrm{Ca})}$, respectively (Fig. 3D). In order to further examine the hypothesis that the target of J-ACTX-Hv1c is an insect $\mathrm{K}_{\mathrm{Ca}}$ channel we investigated if the toxin could produce an additional block in the presence of maximal concentrations of ChTx. Following inhibition of $I_{\mathrm{K}}$ with $30 \mathrm{nM}$ ChTx, subsequent application of $1 \mu \mathrm{M}$ J-ACTX-Hv1c failed to produce any additional block (Fig. 3E). In the complementary experiment, $30 \mathrm{nM}$ ChTx failed to produce any additional block of $I_{\mathrm{K}}$ following inhibition of the current with $1 \mu \mathrm{M} \mathrm{J}$-ACTX-Hv1c (Fig. 3F). These findings provide further evidence that these peptides act on the same molecular target in insect DUM neurons, namely $\mathrm{K}_{\mathrm{Ca}}$ channels.

The effect of J-ACTX-Hv1c on $I_{\mathrm{K}(\mathrm{Ca})}$ was invertebrate-selective as the toxin failed to block either macroscopic outward $K_{\mathrm{V}}$ currents in rat DRG neurons (Fig. 3B, $n=4$ ) or $I_{K(\mathrm{Ca})}$ in these neurons (Fig. 3C, $n=4$ ) isolated using the same current subtraction routine as described earlier. Block of $I_{\mathrm{K}(\mathrm{Ca})}$ occurred without significant alteration of the voltage-dependence of $\mathrm{K}_{\mathrm{Ca}}$ channel activation, including both the $I_{\mathrm{K}(\mathrm{Ca})}$ threshold and $\mathrm{V}_{1 / 2}$ (Figs $\left.4 \mathrm{~A}-\mathrm{D}\right)$. .

\section{Effects on Slo channels.}

The above findings suggest that J-ACTX-Hv1c selectively blocks cockroach $\mathrm{BK}_{\mathrm{Ca}}$ channels rather than small- ( $\left.\mathrm{SK}_{\mathrm{Ca}}, \mathrm{K}_{\mathrm{Ca}} 2 . \mathrm{x}\right)$ and intermediate-conductance ( $\left.\mathrm{IK}_{\mathrm{Ca}}, \mathrm{K}_{\mathrm{Ca}} 3 . \mathrm{x}\right) \mathrm{K}_{\mathrm{Ca}}$ channels. First, the $I_{K(\mathrm{Ca})}$ in cockroach DUM neurons was voltage-activated, like all known $\mathrm{BK}_{\mathrm{Ca}}$ currents, whereas $\mathrm{SK}_{\mathrm{Ca}}$ and $\mathrm{IK}_{\mathrm{Ca}}$ channel currents are voltage-insensitive. Second, no apamin-sensitive SK ${ }_{\mathrm{Ca}}$ channels have been found in isolated cockroach DUM neurons [13]. Nevertheless, we confirmed that J-ACTX-Hv1c specifically blocks insect $\mathrm{BK}_{\mathrm{Ca}}$ channels by examining its effect 
on cockroach $\mathrm{BK}_{\mathrm{Ca}}(p S l o)$ channels heterologously expressed in HEK293 cells. For these experiments we used the AAAA $\Delta$ splice variant that is strongly expressed in octopaminergic DUM neurons [14].

Consistent with previous reports [14], application of $10 \mathrm{mM}$ TEA or $1 \mu \mathrm{M}$ ChTx produced an $84.1 \pm 1.5 \%(n=31)$ and $80.1 \pm 2.1 \%(n=19)$ block, respectively, of $p S l o$ currents activated by depolarizing pulses to $+40 \mathrm{mV}$. J-ACTX-Hv1c caused a concentration-dependent block of pSlo currents with an $\mathrm{IC}_{50}$ of $240 \mathrm{nM}$ (Fig. 5A, C). This $\mathrm{IC}_{50}$ is 83 -fold higher than that observed on DUM neuron $I_{\mathrm{K}(\mathrm{Ca})}$ but similar to the $\mathrm{IC}_{50}$ of $150 \mathrm{nM}$ previously reported for ChTx on pSlo [14]. The time constant $\left(t_{\text {on }}\right)$ for block of pSlo currents by $300 \mathrm{nM} \mathrm{J-ACTX-Hv1c} \mathrm{was} 102 \mathrm{~s}$ but the block was only partially reversible upon washout (Fig. 5D).

In contrast to its action on pSlo channels, J-ACTX-Hv1c only inhibited mSlo channels at much higher concentrations, with an estimated $\mathrm{IC}_{50}$ of $>9.7 \mu \mathrm{M}$ (Fig. 5B, C). J-ACTX-Hv1c did not significantly shift the voltage-dependence of Slo channel activation (Figs 5E-G) nor did it alter the kinetics of channel activation (Fig. 5A, F). Similar to ChTx [15], the block of pSlo currents was voltage-dependent (Fig. 5G) suggesting that the blocker enters the electric field within the pore or interacts with permeant ions within the field. In this scenario, opening of the channel in response to large depolarizations would occur because the toxin dissociates from the pore. In support, alanine mutants of the pseudo-dyad $\left(\mathrm{Arg}^{8}\right.$ and $\mathrm{Tyr}^{31}$ ) are inactive [4], consistent with $\mathrm{Arg}^{8}$ being important in binding to the pore region (see below) as is the case for $\mathrm{Lys}^{27}$ in ChTx (see Fig. 1G and [16]). 


\section{Mapping the toxin pharmacophore}

The functionally critical residues of J-ACTX-Hv1c were previously mapped using alanine-scanning mutagenesis $[4,5]$. This revealed a bipartite epitope comprising residues $\operatorname{Arg}^{8}$, $\mathrm{Pro}^{9}$, and $\mathrm{Tyr}^{31}$ and the two residues that form the vicinal disulfide $\left(\mathrm{Cys}^{13}\right.$ and $\left.\mathrm{Cys}^{14}\right)$. It was proposed that two additional residues, $\mathrm{IIe}^{2}$ and $\mathrm{Val}^{29}$, act as 'gasket' residues that exclude bulk solvent from the putative target binding site [4]. However, since toxin activity was examined using a fly lethality assay it is possible that some of these residues are not important for interaction with $\mathrm{BK}_{\mathrm{Ca}}$ channels per se but rather are important for conferring resistance to proteases and/or the ability of the toxin to penetrate anatomical barriers. Thus, we decided to directly examine whether the functionally critical non-cysteine residues are critical for interaction with insect $\mathrm{BK}_{\mathrm{Ca}}$ channels. $\mathrm{Ile}^{2}$ was not investigated as it is not conserved in all J-ACTX-1 family members (Fig. 1A). CD spectra revealed that none of the mutations used in this study induced perturbations of the toxin structure [4].

The activity of the mutant toxins was examined using DUM neurons, rather than pSlo-expressing HEK293 cells, for two reasons. First, it is possible that an as yet unknown subunit modulates the pharmacology of $\mathrm{BK}_{\mathrm{Ca}}$ blockers on insect Slo channels [17], evident from the higher potency of ChTx on native neurons [14]. Second, the lower potency of the wild-type toxin on pSlo channels would necessitate testing of relatively high concentrations of the mutants to determine their $\mathrm{IC}_{50}$ values. Dose-response curves revealed that the $\mathrm{IC}_{50}$ values for the block of DUM neuron $I_{\mathrm{K}(\mathrm{Ca})}$ by the R8A, P9A and Y31A mutants was 1620-, 100-, and >10,000-fold higher, respectively, than the $\mathrm{IC}_{50}$ value recorded for wild-type toxin (Fig. 6D-G), consistent with the critical roles identified for those residues in previous insect lethality assays [4]. The V29A mutation caused a 7.5-fold decrease in block of $I_{\mathrm{K}(\mathrm{Ca})}$ (Fig. 6D, G, H), consistent with its less critical role in 
insecticidal activity [4].

\section{Chemical features of the toxin pharmacophore}

To further probe the functional relevance of these residues and to investigate the role of individual chemical moieties in the toxin's interaction with insect $\mathrm{BK}_{\mathrm{Ca}}$ channels, we designed a panel of additional mutants and determined their $\mathrm{IC}_{50}$ for inhibition of DUM neuron $I_{\mathrm{K}(\mathrm{Ca})}$ as well as their $\mathrm{LD}_{50}$ when injected into house flies (Musca domestica). We first addressed the functional role of $\mathrm{Arg}^{8}$, the only charged residue in the pharmacophore, by construction of R8E, R8K, R8H and R8Q mutants. We previously showed that introducing a negative charge (R8E) results in a dramatic decrease in insecticidal activity, implying that the positively charged $\delta$-guanido group contributes significantly to target binding [4]. If $\operatorname{Arg}^{8}$ makes an ionic interaction with a negatively charged group on the target, then an R8E mutation would be expected to reduce potency even more than an R8A mutation because it will introduce repulsive electrostatic interactions. While the R8E mutant exhibited a marked 2237-fold reduction in block of $I_{\mathrm{K}(\mathrm{Ca})}$ relative to wild-type toxin (Fig. $6 \mathrm{E}, \mathrm{H}$ ), its $\mathrm{IC}_{50}$ and $\mathrm{LD}_{50}$ values were nevertheless only 1.4-fold and 2.8-fold higher, respectively, than the R8A mutant (Fig. 6H). Moreover, replacement of the $\operatorname{Arg}^{8}$ sidechain with the slightly shorter Lys sidechain caused a dramatic 226-fold reduction in $\mathrm{IC}_{50}$ (Fig. 6B, E, H) and 31-fold reduction in $\mathrm{LD}_{50}$ even though the positive charge on the sidechain is maintained.

In striking contrast, an $\mathrm{R} 8 \mathrm{H}$ mutant was 28 -fold more potent at blocking $I_{\mathrm{K}(\mathrm{Ca})}$ than the $\mathrm{R} 8 \mathrm{~K}$ mutant. Indeed, this mutant is only 8.2-fold less potent than the native toxin (Fig. 6A, E, H). The His sidechain is much shorter than both Arg and Lys and is only slightly charged at physiological $\mathrm{pH}$. These results therefore suggest that the capacity of the residue at position 8 to act as a 
hydrogen bond donor/acceptor is as important as its ability to present a positive charge to the channel. Hydrogen-bonding capacity alone is not sufficient for a high-affinity interaction with insect $\mathrm{BK}_{\mathrm{Ca}}$ channels since an $\mathrm{R} 8 \mathrm{Q}$ mutant is much less potent than $\mathrm{R} 8 \mathrm{~K}$ and $\mathrm{R} 8 \mathrm{H}$ mutants and only slightly more potent than an R8A mutant (Fig. 6E, H).

We next probed the critical features of $\mathrm{Tyr}^{31}$ by measuring the ability of mutants in which $\mathrm{Tyr}^{31}$ was replaced with Phe, Trp, Ile, Leu, Val or Ala to block $I_{\mathrm{K}(\mathrm{Ca})}$ in cockroach DUM neurons (Fig. 6F). The Y31F and, to a lesser extent, Y31W mutants displayed almost wild-type activity (Fig. 6C, F, H), indicating that the hydroxyl group is relatively unimportant and that the aromatic ring is the more critical functional moiety of $\mathrm{Tyr}^{31}$ for interaction with insect $\mathrm{K}_{\mathrm{Ca}}$ channels. Substitution of the aromatic ring with smaller hydrophobes produced mixed results. Y31I, tested only in the fly assay because of limited quantities, was almost fully active (Fig. 6H), while Y31L was significantly less active in both DUM neurons and flies (Fig. 6F, H). This suggests that the key requirement at this position in the toxin pharmacophore is a medium-sized hydrophobe since an aromatic residue is clearly not essential given the high toxicity of the Y31I mutant.

\section{DISCUSSION}

\section{The Janus-faced atracotoxins specifically target insect $\mathrm{BK}_{\mathrm{Ca}}$ channels}

The Janus-faced atracotoxins are a unique family of excitatory peptide toxins that contain a rare vicinal disulfide bond. Despite significant interest in this class of peptides as bioinsecticides [18, 19], their molecular target has until now proven elusive. In the present study we have shown that J-ACTX-Hv1c, the prototypic member of this class of toxins, is a high-affinity blocker of insect $\mathrm{BK}_{\mathrm{Ca}}$ channels. Notably, this block occurred in the absence of any significant changes in the 
voltage-dependence of $\mathrm{K}_{\mathrm{Ca}}$ channel activation. Thus, in contrast with other spider toxins that target $\mathrm{K}_{\mathrm{V}}$ channels [20], J-ACTX-Hv1c appears to be a channel blocker, like charybdotoxin, rather than a gating modifier. Moreover, J-ACTX-Hv1c appears to have high molecular specificity, since other insect $\mathrm{Na}_{\mathrm{V}}, \mathrm{Ca}_{\mathrm{V}}$ and $\mathrm{K}_{\mathrm{V}}$ channel currents were unaffected by toxin concentrations that substantially reduced $I_{\mathrm{K}(\mathrm{Ca}) \text {. }}$

The specific action of J-ACTX-Hv1c on insect $\mathrm{BK}_{\mathrm{Ca}}$ channels was confirmed by block of $\mathrm{BK}_{\mathrm{Ca}}$ currents mediated by the $\alpha$-subunit of the cockroach pSlo channel. While the $\mathrm{IC}_{50}$ for block by J-ACTX-Hv1c (240 nM) was higher than for the native $\mathrm{BK}_{\mathrm{Ca}}$ channel in DUM neurons, the loss of potency parallels that seen with ChTx, with an increase in $\mathrm{IC}_{50}$ from 1.9 to $158 \mathrm{nM}$ [14]. This may be due to the absence of a modulatory subunit since the $\beta$-subunit of human $h$ Slo channels causes a 50-fold increase in the affinity of ChTx for these channels [21]. Consistent with this hypothesis, the activation kinetics of native $I_{\mathrm{K}(\mathrm{Ca})}$ in DUM neurons were much more rapid than pSlo channel currents, as previously noted [14], similar to the more rapid onset and inactivation of currents when mammalian Slo channels are expressed in association with $\beta 2$ and $\beta 3$ subunits [22-24]. Homologs of mammalian $\beta$ subunits have not been detected in the genomes of Drosophila or C. elegans [25], and dSlo currents are not functionally affected by coexpression with a mammalian $\beta 1$ subunit [26]. However, gating of $d S l o$ channels is modulated by co-expression with Slowpoke binding protein (Slob) [27], indicating that insects may possess novel subunits not present in vertebrates for regulating the activity of $\mathrm{BK}_{\mathrm{Ca}}$ channels. However, until the putative regulatory subunits associated with the pSlo channel have been identified, the native phenotype cannot be reconstituted and the influence of these subunits on the affinity of JACTX-Hv1c for $p S l o$ channels cannot be determined. 
Since we have demonstrated that J-ACTX-Hv1c is a specific, high-affinity blocker of insect $\mathrm{BK}_{\mathrm{Ca}}$ channels, we propose that it be renamed $\kappa$-ACTX-Hv1c to be consistent with the rational nomenclature proposed earlier for naming spider toxins whose molecular target has been established [28].

\section{Mode of interaction of J-ACTX-Hv1c with insect BK $\mathrm{Ca}_{\mathrm{a}}$ channels}

Scorpion toxins from $\alpha$-KTx subfamilies 1-3 block $\mathrm{BK}_{\mathrm{Ca}}$ channels in the vicinity of the selectivity filter, mainly via residues in their C-terminal $\beta$-hairpin [16]. Despite its ability to block $\mathrm{BK}_{\mathrm{Ca}}$ channels, J-ACTX-Hv1c has virtually no sequence homology with scorpion $\mathrm{BK}_{\mathrm{Ca}}$ blockers, particularly in the functionally critical $\beta$-hairpin region (Fig. 1B). Moreover, superposition of the 3D structure of J-ACTX-Hv1c [1] with that of ChTx [29] demonstrates that the backbone folds of the two toxins are significantly different (Fig. 1F). This raises the question of whether the two toxins interact in fundamentally different ways with insect $\mathrm{BK}_{\mathrm{Ca}}$ channels.

We previously speculated that the functional Lys-Tyr/Phe dyad that is largely conserved in toxins that target vertebrate $\mathrm{K}_{\mathrm{v}}$ channels [30] might also be present in J-ACTX-Hv1c if Arg is considered a suitable substitute for Lys [4]. The "pseudo-dyad" of J-ACTX-Hv1c is topologically similar to that of ChTx (Fig. 1G) although the overlay is not as good as with the dyad of the $\mathrm{K}_{\mathrm{V}}$ channel blockers BgK and agitoxin 2 [4]. However, since we demonstrated in the present study that Lys is a poor substitute for the functionally critical $\mathrm{Arg}^{8}$ residue in J-ACTX, then this apparent similarity to the dyad of vertebrate $\mathrm{K}_{\mathrm{V}}$ channel toxins is likely to be coincidental and not predictive of the mode of binding of J-ACTX-Hv1c to insect $\mathrm{BK}_{\mathrm{Ca}}$ channels. 
Several lines of evidence suggest that J-ACTX-Hv1c and ChTx engage $\mathrm{BK}_{\mathrm{Ca}}$ channels via quite different molecular mechanisms. First, the pharmacophore of J-ACTX-Hv1c is much smaller and involves far fewer residues than that of ChTx (see Fig. 1D, E). Second, in contrast to ChTx and other toxins that target $\mathrm{K}^{+}$channels $[31,32]$, the block of $\mathrm{BK}_{\mathrm{Ca}}$ channels by $\mathrm{J}$-ACTX-Hv1c is significantly less voltage-dependent (Fig. 5G). This suggests that J-ACTX-Hv1c does not bind as deeply into the extracellular mouth of the ion channel pore as these other toxins. This is likely due to the bifurcated $\delta$-guanidinium group at the tip of the critical $\operatorname{Arg}^{8}$ residue, which is much bulkier than the single amine moiety at the tip of the linear sidechain of the key Lys $^{27}$ residue in ChTx. Consistent with this hypothesis, a K27R mutant of ChTx is 4-fold less potent on mammalian $\mathrm{BK}_{\mathrm{Ca}}$ channels [33] and the voltage-dependency of block is significantly reduced compared with native toxin. Third, the ability of His, as opposed to Lys, to effectively substitute for $\mathrm{Arg}^{8}$ in J-ACTX-Hv1c suggests that factors other than electrostatic charge are also important at this position in the toxin pharmacophore. Hydrogen-bonding capacity might be critical, since the Arg guanido and His imidazole moieties contain two identically spaced nitrogens that can serve as hydrogen-bond donors/acceptors. It is possible that $\mathrm{Arg}^{8}$ forms hydrogen bonds with surface-exposed carbonyls in the pore region of the $\mathrm{BK}_{\mathrm{Ca}}$ channel. The combined evidence therefore suggests that these two toxins, although both derived from arachnid venoms, have evolved to interact in quite different ways with invertebrate $\mathrm{BK}_{\mathrm{Ca}}$ channels.

\section{J-ACTX-Hv1c as a molecular tool}

Large-conductance $\mathrm{K}_{\mathrm{Ca}}$ channels, also termed $\mathrm{BK}_{\mathrm{Ca}}\left(\mathrm{K}_{\mathrm{Ca}} 1.1\right)$, Maxi-K or Slo1 channels, are activated by an increase in intracellular $\mathrm{Ca}^{2+}$ and by depolarization [34]. These channels play an important role in controlling calcium homeostasis, excitability and action potential waveform, 
and $\mathrm{BK}_{\mathrm{Ca}}$ currents prevent excessive $\mathrm{Ca}^{2+}$ entry by contributing to action potential repolarization and membrane hyperpolarization [12]. It has been suggested that activators and blockers of $\mathrm{BK}_{\mathrm{Ca}}$ channels may have application as neuroprotectants or as therapeutics in certain disease states including vascular dysfunction, urinary disease, and certain seizure conditions [35]

Study of invertebrate $\mathrm{BK}_{\mathrm{Ca}}$ channels would be enhanced by the availability of a readily-available, high-affinity blocker that is devoid of activity on other ion channels. While ChTx and J-ACTX-Hv1c block cockroach $\mathrm{BK}_{\mathrm{Ca}}$ channels with similar affinity, J-ACTX-Hv1c offers several potential advantages as a research tool for invertebrate studies. First, in addition to its block of $\mathrm{BK}_{\mathrm{Ca}}$ channels, ChTx also blocks $\mathrm{K}_{\mathrm{V}}$ channels with moderate affinity [36]. In contrast, even at very high concentrations, J-ACTX-Hv1c has very limited activity against $\mathrm{K}_{\mathrm{V}}$ channels. Second, a bacterial expression system has been developed that allows recombinant J-ACTX-Hv1c to be produced cheaply and easily [4]. Third, since the binding epitope for JACTX-Hv1c has been mapped, point mutants that could be used for negative controls can be readily produced using this bacterial expression system.

\section{$\mathrm{BK}_{\mathrm{Ca}}$ channels: a potential insecticide target?}

A major bottleneck in the development of new insecticides has been the difficulty in identifying new molecular targets. Indeed, the vast majority of chemical insecticides are directed against one of five targets (four of which are ion channels) in the insect nervous system [18, 37]. Although $\mathrm{BK}_{\mathrm{Ca}}$ channels play important roles in the excitability of insect neurons and muscles [38], they have not been considered potential insecticide targets since no insect-selective ligands of these channels have previously been identified. However, our demonstration that the insect-selective spider toxin J-ACTX-Hv1c is a high-affinity blocker of insect $\mathrm{BK}_{\mathrm{Ca}}$ channels has, for the first 
time, identified this channel as a potential insecticide target.

Interestingly, paxilline, a well-known mammalian $\mathrm{BK}_{\mathrm{Ca}}$ channel blocker [39], as well as several other structurally-related indole-diterpenes, are toxic to a wide range of insect genera [40-42]. In order to determine whether the insecticidal activity of these diterpenes might stem from their activity on $\mathrm{BK}_{\mathrm{Ca}}$ channels, we examined their ability to block $I_{\mathrm{K}(\mathrm{Ca})}$ in cockroach DUM neurons. Importantly, paxilline blocked both the fast-transient and late-sustained $I_{\mathrm{K}(\mathrm{Ca})}$, with $\mathrm{IC}_{50}$ values of 17.1 and $16.0 \mathrm{nM}(n=7-9)$ respectively (data not shown). This supports our contention that inhibition of $\mathrm{BK}_{\mathrm{Ca}}$ channels may contribute to their lethality to in insects and that insect $\mathrm{BK}_{\mathrm{Ca}}$ channels might therefore be potential insecticide targets.

'Short-chain’ scorpion $\alpha$-KTx 1 family toxins, such as ChTx ( $\alpha$-KTx 1.1) and iberiotoxin (IbTx, $\alpha$-KTx 1.3), are frequently used as molecular tools to study $\mathrm{BK}_{\mathrm{Ca}}$ channels. However, these toxins are poor leads for development of insecticides that block invertebrate $\mathrm{BK}_{\mathrm{Ca}}$ channels since they have limited phyletic selectivity, with a tendency to be more active against vertebrate channels (Table 1). For example, ChTx blocks mammalian Slo channels ( $\mathrm{IC}_{50}$ values of 36 and

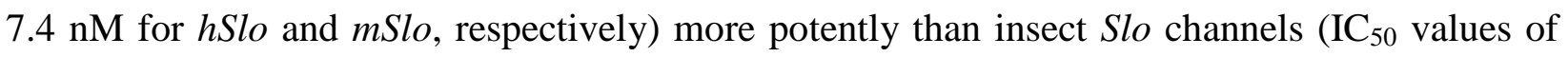
$158 \mathrm{nM}$ and $>5 \mu \mathrm{M}$ for $p$ Slo and $d S$ Slo, respectively) [14, 43]. In contrast, J-ACTX-Hv1c is highly selective for insect $\mathrm{BK}_{\mathrm{Ca}}$ channels: it blocks cockroach $\mathrm{BK}_{\mathrm{Ca}}$ channels at low nanomolar concentrations and shows a 41-fold preference for pSlo over mSlo (Table 1). Since JACTX-Hv1c is a pore blocker, and the pore regions of $m S l o, r S l o$, and $h$ Slo are identical (see Fig. 7), we predict that J-ACTX-Hv1c will also have little effect on rSlo and hSlo channels. Consistent with this hypothesis, J-ACTX-Hv1c failed to inhibit $\mathrm{BK}_{\mathrm{Ca}}$ currents in rat DRG 
neurons (which express rSlo) and it was previously shown that subcutaneous injection of JACTX-Hv1c into newborn mice, at five times the $\mathrm{LD}_{50}$ dose in insects, fails to produce any overt signs of toxicity [1]. Moreover, J-ACTX-Hv1c failed to alter neurotransmission in an isolated chick biventer cervicis nerve-muscle preparation [1].

$\mathrm{BK}_{\mathrm{Ca}}$ channels have been highly conserved throughout evolution, and therefore it may seem surprising that toxins can discriminate between invertebrate $\mathrm{BK}_{\mathrm{Ca}}$ channels and their vertebrate counterparts. However, insect and mammalian Slo channels display several important differences in the pore region between the S5 and S6 transmembrane helices (Fig. 7), which is believed to be the primary site of interaction with ChTx, IbTx, and most likely J-ACTX-Hv1c [36]. Remarkably, the phyletic selectivity of ChTx can be manipulated by a single point mutation in this region. For example, $\mathrm{BK}_{\mathrm{Ca}}$ channels from fruit flies and cockroaches become significantly more sensitive to ChTx, a vertebrate-specific $\mathrm{BK}_{\mathrm{Ca}}$ blocker, when individual pore residues are mutated to that found in the corresponding position in vertebrate Slo channels; these mutants include T290E in Drosophila dSlo [43] and Q285K in cockroach pSlo [14] (see Fig. 7). Thus, the amino acid variation in the pore region of the $\mathrm{BK}_{\mathrm{Ca}}$ channel appears sufficient to explain the insect selectivity of J-ACTX-Hv1c.

J-ACTX-Hv1c is active against a diverse range of insect phyla $[1,4,6]$ and therefore insecticides that target this channel might find wide application in the control of arthropod pests. The molecular epitope on this peptide toxin that mediates its interaction with insect $\mathrm{BK}_{\mathrm{Ca}}$ channels comprises only five spatially proximal residues (this study and [4]). Since J-ACTX-Hv1c has 870-fold higher selectivity for insect $\mathrm{BK}_{\mathrm{Ca}}$ channels than ChTx, this epitope should provide a convenient template for the rational design of small-molecule insecticides that selectively target 
insect $\mathrm{BK}_{\mathrm{Ca}}$ channels.

\section{MATERIALS AND METHODS}

\section{Construction and Purification of J-ACTX-Hv1c}

Mutants-Single point mutations were introduced using complementary mutagenic PCR primers using pFM1 as a template. This plasmid encodes a synthetic J-ACTX-Hv1c gene with codons optimised for expression in Escherichia coli [4]. Mutant gene sequences were amplified, digested with Bam HI and Eco RI, and subcloned into the pGEX-2T vector using standard methods. The resultant plasmids encode a synthetic toxin gene fused to the 3 ' end of the gene for glutathione $S$ transferase (GST), with an intervening thrombin cleavage site. Engineered plasmids were transformed into E. coli BL21 cells for protein expression. Cells were grown at $37^{\circ} \mathrm{C}$ in $\mathrm{LB}$ medium to an $\mathrm{OD}_{600}$ of $0.6-0.8$ before induction with $300 \mu \mathrm{M}$ IPTG. Cells were harvested by centrifugation at an $\mathrm{OD}_{600}$ of 1.9-2.1 and lysed by sonication. GST-toxin fusion proteins were purified by affinity chromatography on a GSH-Sepharose (Amersham Biosciences) column, then cleaved on-column with thrombin to release recombinant J-ACTX-Hv1c. Toxin was eluted from the column with buffer and further purified by reverse-phase HPLC using a Vydac C18 analytical column (4.6 x $250 \mathrm{~mm}, 5-\mu \mathrm{m}$ pore size). HPLC was performed using a linear gradient of $15-22 \%$ acetonitrile over $15 \mathrm{~min}$ at a flow rate of $1 \mathrm{ml} / \mathrm{min}$. Correctly folded toxin eluted as the major peak with a retention time of 9-12 min depending on the mutant purified. Toxin masses were verified by electrospray mass spectrometry.

\section{Circular Dichroic Spectropolarimetry}

Far-UV circular dichroic (CD) spectra (185-260 nm) were recorded on a Jasco J-715 spectropolarimeter at $4^{\circ} \mathrm{C}$. Peptides were dissolved to $25 \mathrm{mM}$ in sterile water and loaded into a 
0.1-cm rectangular quartz cell for analysis. Final spectra were the average of eight scans using a scan rate of $20 \mathrm{~nm} / \mathrm{min}$ and a response time of $4 \mathrm{~s}$. A water blank run under identical conditions was subtracted from each toxin spectrum.

\section{Lethality Assays}

House flies (Musca domestica) weighing 9-20 mg were injected with 1-2 $\mu$ l of toxin diluted in insect saline [44] at a concentration range of 10-106 pmol/g. Each test dose was administered to 10 flies and performed in duplicate. Control flies received $2 \mu \mathrm{l}$ of insect saline. All injections were dispensed with a 29-gauge needle using an Arnold microapplicator (Burkhard Scientific Supply). Flies were injected in the dorsal thorax while immobilized at $4^{\circ} \mathrm{C}$, then transferred to room temperature. The dose corresponding to $50 \%$ lethality of the test population $24 \mathrm{~h}$ after injection $\left(\mathrm{LD}_{50}\right)$ was calculated using the following equation.

$$
Y=\frac{100}{1+\left(\frac{L D_{50}}{x}\right)^{n_{H}}}
$$

where $Y$ is the percentage response at the dose $(x)$, and $\mathrm{n}_{\mathrm{H}}$ is the slope (Hill) coefficient.

\section{Electrophysiology}

Whole-cell recordings of ionic currents were made using an Axopatch 200A amplifier. Patch pipettes were pulled from borosilicate glass and had resistances of 1-2 M $\Omega$ for $I_{\mathrm{Na}}$ recordings and 2-4 $\mathrm{M} \Omega$ for $I_{\mathrm{Ca}}, I_{\mathrm{K}}$ and Slo channel current recordings. The holding potential was $-80 \mathrm{mV}$, unless stated otherwise. External solution was administered via a continuous gravity-fed perfusion system at $\sim 1.0 \mathrm{ml} / \mathrm{min}$ and a temperature of $20-23^{\circ} \mathrm{C}$. Toxins were applied via a pressurized fast perfusion system (Automate Scientific). The osmolarity of all internal and external solutions was 
adjusted to within $\pm 5 \mathrm{mOsmol} / \mathrm{l}$ with sucrose to reduce osmotic stress. Experiments were rejected if there were large leak currents or currents showed signs of poor space clamping. Stimulation and recording were controlled by AxoData or pClamp data acquisition systems (Axon Instruments). Data was filtered at $5 \mathrm{kHz}$ (low-pass Bessel filter) with digital sampling rates between 15 and $25 \mathrm{kHz}$ depending on voltage protocol length. Leakage and capacitive currents were digitally subtracted with $P-P / 4$ procedures and series resistance compensation was $>80 \%$ for all cells. The liquid junction potential was determined using JPCalc [45], and all data were compensated for this value. Analysis parameters were as described [46].

\section{DUM neuron $\mathrm{Na}_{v}, \mathrm{Ca}_{v}$ and $\mathrm{K}_{\mathrm{v}}$ channel currents}

DUM neuron cell bodies were isolated from the terminal abdominal ganglion of the American cockroach Periplaneta americana as described [47]. The TAG was dissected and placed in sterile $\mathrm{Ca}^{2+}$-free normal insect saline (NIS) containing (in mM): $\mathrm{NaCl} 200, \mathrm{KCl} 3.1, \mathrm{MgCl}_{2} 4, \mathrm{~N}-$ hydroxyethylpiperazine-N-ethanesulphonic acid (HEPES) 10, sucrose 30, D-glucose 20, pH 7.4. The ganglia were then desheathed and incubated for $20 \mathrm{~min}$ in $\mathrm{Ca}^{2+}$-free NIS containing Type IA collagenase ( $2 \mathrm{mg} / \mathrm{ml})$. Subsequently, the ganglia were rinsed three times in NIS, containing 5 $\mathrm{mM} \mathrm{CaCl} 2,5 \% \mathrm{v} / \mathrm{v}$ bovine calf serum, penicillin (50 IU/ml) and streptomycin (50 $\mu \mathrm{g} / \mathrm{ml})$ (Trace Biosciences). Single cells were mechanically isolated by trituration. The resulting suspension was then allowed to adhere overnight to glass coverslips which had been previously been coated with concanavalin-A (2 mg/ml) (Sigma Chemicals). Large tear-shaped DUM neurons with diameters of $>45 \mu \mathrm{m}$ were selected for experiments.

To record voltage-activated $\mathrm{Na}^{+}\left(\mathrm{Na} \mathrm{V}_{\mathrm{V}}\right.$ ) channel currents $\left(I_{\mathrm{Na}}\right.$ ), pipettes contained (in $\mathrm{mM}$ ): $\mathrm{NaCl}$ 
20, CsF 135, $\mathrm{MgCl}_{2} 1$, ethylene glycol-bis( $\beta$-aminoethyl ether)- $N, N, N^{\prime}, N^{\prime}$-tetraacetic acid (EGTA) 5, D-glucose 10, and HEPES 10, pH 7.4. The external solution contained (in mM): $\mathrm{NaCl}$ 130, $\mathrm{CsCl}$ 5, TEA-Cl 20, $\mathrm{CaCl}_{2}$ 1.8, 4-aminopyridine (4-AP) 5, verapamil-HCl 0.01, $\mathrm{NiCl}_{2}$ 0.1, $\mathrm{CdCl}_{2} 1$ and HEPES 10, $\mathrm{pH}$ 7.4. To record voltage-activated $\mathrm{Ca}^{2+}(\mathrm{Cav})$ channel currents $\left(I_{\mathrm{Ca}}\right)$, pipettes contained (in $\mathrm{mM}$ ): $\mathrm{CsCl}$ 110, Na-acetate 10, $\mathrm{ATP}^{-\mathrm{Na}_{2}} \quad 2, \mathrm{CaCl}_{2} \quad 0.5$, tetraethylammonium (TEA)-Br 50, EGTA 10, HEPES 10, pH 7.4. The external solution contained (in mM): Na-acetate 160, TEA-Br 30, $\mathrm{CaCl}_{2}$ 5, HEPES 10, 150 nM TTX, pH 7.4. To record delayed-rectifier $\left(I_{\mathrm{K}(\mathrm{DR})}\right)$, transient 'A-type' $\left(I_{\mathrm{K}(\mathrm{A})}\right)$ and $\mathrm{K}_{\mathrm{Ca}}\left(I_{\mathrm{K}(\mathrm{Ca})}\right)$ channel currents, pipettes contained (in mM): $\mathrm{KCl}$ 135, $\mathrm{KF} 25, \mathrm{NaCl}$ 9, ATP- $\mathrm{Na}_{2} 3, \mathrm{CaCl}_{2}$ 0.1, $\mathrm{MgCl}_{2}$ 1, EGTA 1, HEPES 10, pH 7.4. External solutions contained (in mM): $\mathrm{NaCl} 100, \mathrm{KCl} 30, \mathrm{CaCl}_{2} 5, \mathrm{MgCl}_{2}$ 1.5, D-glucose 10, HEPES 10, $150 \mathrm{nM}$ TTX, pH 7.4. Since $I_{\mathrm{Na}}$ were blocked by TTX, any involvement of $\mathrm{Na}^{+}$-dependent $I_{\mathrm{K}}$ were eliminated. To record $I_{\mathrm{K}(\mathrm{DR})}$ in isolation, $5 \mathrm{mM}$ 4-AP, 1 $\mathrm{mM} \mathrm{CdCl}_{2}$ and $30 \mathrm{nM}$ charybdotoxin (ChTx) were also added to the external solution to

eliminate $I_{\mathrm{K}(\mathrm{A})}$ [13] and $I_{\mathrm{K}(\mathrm{Ca})}$ (see Results). $I_{\mathrm{K}(\mathrm{A})}$ were elicited in the presence of $1 \mathrm{mM} \mathrm{CdCl}_{2}$ and $30 \mathrm{nM}$ ChTx and isolated using current subtraction routines following a two-pulse protocol to inactivate $I_{\mathrm{K}(\mathrm{A})}$ (see Results). $I_{\mathrm{K}(\mathrm{Ca})}$ were elicited in the presence of $5 \mathrm{mM}$ 4-AP and isolated from $I_{\mathrm{K}(\mathrm{DR})}$ using current subtraction routines following addition of $1 \mathrm{mM} \mathrm{CdCl} 2$ and $30 \mathrm{nM} \mathrm{ChTx}$ (see Results).

\section{DRG neuron $\mathrm{K}_{\mathrm{v}}$ channel currents}

Acutely dissociated dorsal root ganglion (DRG) neurons were prepared from 5 to 14-day-old Wister rats and maintained in short-term primary culture as described [48]. Small- to mediumsized DRG neurons with diameters of 18-45 $\mu \mathrm{m}$ were selected for experiments as they have 
previously been shown to express $\mathrm{BK}_{\mathrm{Ca}}$ channels [49]. To record $I_{\mathrm{K}(\mathrm{Ca})}$ pipettes contained (in $\mathrm{mM}$ ): $\mathrm{KCl}$ 140, tetramethylammonium (TMA)-Cl 50, $\mathrm{CaCl}_{2}$ 0.5, D-glucose 5, EGTA 1 and HEPES 5, pH 7.0. The external solution contained (in mM): TMA-Cl $120 \mathrm{KCl}$ 5, NaCl 30, $\mathrm{MgCl}_{2}$ 1, $\mathrm{CaCl}_{2}$ 1.8, D-glucose 25, 4-AP 5, $300 \mathrm{nM}$ TTX, HEPES 5, pH 7.2. Following completion of the experiment, the presence of $I_{\mathrm{K}(\mathrm{Ca})}$ was confirmed by perfusion with $1 \mathrm{mM}$ $\mathrm{CdCl}_{2}$ and $100 \mathrm{nM}$ ChTx. $I_{\mathrm{K}(\mathrm{Ca})}$ was then isolated by subtraction from residual $I_{\mathrm{K}}$.

\section{Slo channel currents}

HEK293 cells were maintained in Dulbecco's Modified Eagle's Medium supplemented with $10 \% \mathrm{v} / \mathrm{v}$ bovine calf serum and L-glutamine $(1 \mathrm{mM})$. Expression of pSlo and $\mathrm{mSlo}$ was performed by transfection of HEK293 cells with a construct containing the coding region cloned into the expression vector pcDNA3.1, which also carries the G418 resistance gene. Stably transfected cells were then selected with $1 \mathrm{mg} \mathrm{ml}^{-1} \mathrm{G} 418$. These cells were maintained in the normal growth media described above and cultured on sterile glass coverslips. To record Slo channel currents from HEK293 cells pipettes contained (in mM): $\mathrm{NaCl} 4, \mathrm{KCl} 140$, ATP-Mg 2, $\mathrm{CaCl}_{2}$ 0.1, HEPES 10, pH 7.25. The external solution contained (in $\mathrm{mM}$ ): $\mathrm{NaCl} 135, \mathrm{KCl}$, $\mathrm{MgCl}_{2} 1, \mathrm{CaCl}_{2}$ 1, $\mathrm{NaH}_{2} \mathrm{PO}_{4}$ 0.33, D-glucose 10, HEPES 10, pH 7.4.

\section{Acknowledgements}

The authors thank Dieter Wicher and Christian Derst for pSlo and Andy Braun for mSlo expression vectors. This work was supported by Discovery Grants from the Australian Research Council (DP0559396 to G.M.N./G.F.K. and DP0774245 to G.F.K.) and Australian Postgraduate Awards to S.J.G. and M.J.W. Requests for samples of J-ACTX-Hv1c and/or the expression system for production of recombinant toxin should be directed to G.F.K. 


\section{References}

1. Wang X-H, Connor M, Smith R, Maciejewski MW, Howden ME, Nicholson GM, Christie MJ \& King GF (2000) Discovery and characterization of a family of insecticidal neurotoxins with a rare vicinal disulfide bridge. Nature Struct Biol 7, 505-513.

2. Pallaghy PK, Neilsen KJ, Craik DJ \& Norton RS (1994) A common structural motif incorporating a cystine knot and a triple-stranded $\beta$-sheet in toxic and inhibitory polypeptides. Protein Sci 3, 1833-1839.

3. King GF, Tedford HW \& Maggio F (2002) Structure and function of insecticidal neurotoxins from Australian funnel-web spiders. J Toxicol-Toxin Rev 21, 359-389.

4. Maggio F \& King GF (2002) Scanning mutagenesis of a Janus-faced atracotoxin reveals a bipartite surface patch that is essential for neurotoxic function. $J$ Biol Chem 277, 2280622813.

5. Maggio F \& King GF (2002) Role of the structurally disordered N- and C-terminal residues in the Janus-faced atracotoxins. Toxicon 40, 1355-1361.

6. Tedford HW, Maggio F, Reenan RA \& King GF (2007) A model genetic system for testing the in vivo function of peptide toxins. Peptides 28, 51-56.

7. Cestèle S \& Catterall WA (2000) Molecular mechanisms of neurotoxin action on voltagegated sodium channels. Biochimie 82, 883-892.

8. Fletcher JI, Chapman BE, Mackay JP, Howden MEH \& King GF (1997) The structure of versutoxin ( $\delta$-atracotoxin-Hv1) provides insights into the binding of site 3 neurotoxins to the voltage-gated sodium channel. Structure 5, 1525-1535.

9. Bargmann CI (1998) Neurobiology of the Caenorhabditis elegans genome. Science 282, 2028-2033.

10. Nicholson GM, Little MJ \& Birinyi-Strachan LC (2004) Structure and function of $\delta$ atracotoxins: lethal neurotoxins targeting the voltage-gated sodium channel. Toxicon 43, 587-599.

11. Wicher D \& Penzlin $\mathrm{H}$ (1997) $\mathrm{Ca}^{2+}$ currents in central insect neurons: electrophysiological and pharmacological properties. J Neurophysiol 77, 186-199. 
12. Grolleau F \& Lapied B (2000) Dorsal unpaired median neurones in the insect central nervous system: towards a better understanding of the ionic mechanisms underlying spontaneous electrical activity. J Exp Biol 203, 1633-1648.

13. Grolleau F \& Lapied B (1995) Separation and identification of multiple potassium currents regulating the pacemaker activity of insect neurosecretory cells (DUM neurons). $J$ Neurophysiol 73, 160-171.

14. Derst C, Messutat S, Walther C, Eckert M, Heinemann SH \& Wicher D (2003) The large conductance $\mathrm{Ca}^{2+}$-activated potassium channel (pSlo) of the cockroach Periplaneta americana: structure, localization in neurons and electrophysiology. Eur J Neurosci 17, 1197-1212.

15. MacKinnon R \& Miller C (1988) Mechanism of charybdotoxin block of the highconductance, $\mathrm{Ca}^{2+}$-activated $\mathrm{K}^{+}$channel. J Gen Physiol 91, 335-349.

16. Stampe P, Kolmakova-Partensky L \& Miller C (1994) Intimations of $\mathrm{K}^{+}$channel structure from a complete functional map of the molecular surface of charybdotoxin. Biochemistry 33, 443-450.

17. Wicher D, Walther C \& Wicher C (2001) Non-synaptic ion channels in insects-basic properties of currents and their modulation in neurons and skeletal muscles. Prog Neurobiol 64, 431-525.

18. Tedford HW, Sollod BL, Maggio F \& King GF (2004) Australian funnel-web spiders: master insecticide chemists. Toxicon 43, 601-618.

19. Maggio F, Sollod BL, Tedford HW \& King GF (2004) Spider toxins and their potential for insect control. In Comprehensive Molecular Insect Science (Gilbert LI, Iatrou K \& Gill S, ed^eds). Elsevier.

20. Swartz KJ (2007) Tarantula toxins interacting with voltage sensors in potassium channels. Toxicon 49, 213-230.

21. Hanner M, Schmalhofer WA, Munujos P, Knaus HG, Kaczorowski GJ \& Garcia ML (1997) The $\beta$ subunit of the high-conductance calcium-activated potassium channel contributes to the high-affinity receptor for charybdotoxin. Proc Natl Acad Sci USA 94, 2853-2858.

22. Xia XM, Ding JP \& Lingle CJ (2003) Inactivation of BK channels by the $\mathrm{NH}_{2}$ terminus of the $\beta 2$ auxiliary subunit: an essential role of a terminal peptide segment of three hydrophobic residues. J Gen Physiol 121, 125-148. 
23. Wallner M, Meera P \& Toro L (1999) Molecular basis of fast inactivation in voltage and $\mathrm{Ca}^{2+}$-activated $\mathrm{K}^{+}$channels: a transmembrane $\beta$-subunit homolog. Proc Natl Acad Sci USA 96, 4137-4142.

24. Lingle CJ, Zeng XH, Ding JP \& Xia XM (2001) Inactivation of BK channels mediated by the $\mathrm{NH}_{2}$ terminus of the $\beta 3 \mathrm{~b}$ auxiliary subunit involves a two-step mechanism: possible separation of binding and blockade. J Gen Physiol 117, 583-606.

25. Littleton JT \& Ganetzky B (2000) Ion channels and synaptic organization: analysis of the Drosophila genome. Neuron 26, 35-43.

26. Wallner M, Meera P \& Toro L (1996) Determinant for $\beta$-subunit regulation in highconductance voltage-activated and $\mathrm{Ca}^{2+}$-sensitive $\mathrm{K}^{+}$channels: an additional transmembrane region at the N terminus. Proc Natl Acad Sci USA 93, 14922-14927.

27. Schopperle WM, Holmqvist MH, Zhou Y, Wang J, Wang Z, Griffith LC, Keselman I, Kusinitz F, Dagan D \& Levitan IB (1998) Slob, a novel protein that interacts with the Slowpoke calcium-dependent potassium channel. Neuron 20, 565-573.

28. Fletcher JI, Smith R, O'Donoghue SI, Nilges M, Connor M, Howden ME, Christie MJ \& King GF (1997) The structure of a novel insecticidal neurotoxin, $\omega$-atracotoxin-HV1, from the venom of an Australian funnel web spider. Nature Struct Biol 4, 559-566.

29. Bontems F, Roumestand C, Gilquin B, Ménez A \& Toma F (1991) Refined structure of charybdotoxin: common motifs in scorpion toxins and insect defensins. Science 254, 15211523.

30. Dauplais M, Lecoq A, Song J, Cotton J, Jamin N, Gilquin B, Roumestand C, Vita C, Medeiros CLCd, Rowan EG, Harvey AL \& Ménez A (1997) On the convergent evolution of animal toxins. Conservation of a diad of functional residues in potassium channel-blocking toxins with unrelated structures. J Biol Chem 272, 4302-4309.

31. Goldstein SA \& Miller C (1993) Mechanism of charybdotoxin block of a voltage-gated $\mathrm{K}^{+}$ channel. Biophys J 65, 1613-1619.

32. Terlau H, Boccaccio A, Olivera BM \& Conti F (1999) The block of Shaker $\mathrm{K}^{+}$channels by $\kappa$-conotoxin PVIIA is state dependent. J Gen Physiol 114, 125-140.

33. Park CS \& Miller C (1992) Interaction of charybdotoxin with permeant ions inside the pore of a $\mathrm{K}^{+}$channel. Neuron $\mathbf{9}$, 307-313. 
34. Vergara C, Latorre R, Marrion NV \& Adelman JP (1998) Calcium-activated potassium channels. Curr Opin Neurobiol 8, 321-329.

35. Ghatta S, Nimmagadda D, Xu X \& O'Rourke ST (2006) Large-conductance, calciumactivated potassium channels: structural and functional implications. Pharmacol Ther 110, 103-116.

36. Gao YD \& Garcia ML (2003) Interaction of agitoxin2, charybdotoxin, and iberiotoxin with potassium channels: selectivity between voltage-gated and Maxi-K channels. Proteins 52, 146-154.

37. Tedford HW, Gilles N, Ménez A, Doering CJ, Zamponi GW \& King GF (2004) Scanning mutagenesis of $\omega$-atracotoxin-Hv1a reveals a spatially restricted epitope that confers selective activity against invertebrate calcium channels. J Biol Chem 279, 44133-44140.

38. Singh S \& Wu CF (1990) Properties of potassium currents and their role in membrane excitability in Drosophila larval muscle fibers. J Exp Biol 152, 59-76.

39. McMillan LK, Carr RL, Young CA, Astin JW, Lowe RG, Parker EJ, Jameson GB, Finch SC, Miles CO, McManus OB, Schmalhofer WA, Garcia ML, Kaczorowski GJ, Goetz M, Tkacz JS \& Scott B (2003) Molecular analysis of two cytochrome P450 monooxygenase genes required for paxilline biosynthesis in Penicillium paxilli, and effects of paxilline intermediates on mammalian maxi-K ion channels. Mol Genet Genomics 270, 9-23.

40. Li C, Gloer JB, Wicklow DT \& Dowd PF (2002) Thiersinines A and B: novel antiinsectan indole diterpenoids from a new fungicolous Penicillium species (NRRL 28147). Org Lett 4, 3095-3098.

41. Belofsky GN, Gloer JB, Wicklow DT \& Dowd PF (1995) Antiinsectan alkaloids: Shearinines A-C and a new paxilline derivative from the ascostromata of Eupenicillium shearii. Tetrahedron 51, 3959-3968.

42. Li C, Gloer JB, Wicklow DT \& Dowd PF (2005) Antiinsectan decaturin and oxalicine analogues from Penicillium thiersii. J Nat Prod 68, 319-322.

43. Myers MP \& Stampe P (2000) A point mutation in the maxi-K clone dSlo forms a high affinity site for charybdotoxin. Neuropharmacology 39, 11-20.

44. Eitan M, Fowler E, Herrmann R, Duval A, Pelhate M \& Zlotkin E (1990) A scorpion venom neurotoxin paralytic to insects that affects sodium current inactivation - purification, primary structure, and mode of action. Biochemistry 29, 5941-5947. 
45. Barry PH (1994) JPCalc, a software package for calculating liquid junction potential corrections in patch-clamp, intracellular, epithelial and bilayer measurements and for correcting junction potential measurements. J Neurosci Meth 51, 107-116.

46. Birinyi-Strachan LC, Davies MJ, Lewis RJ \& Nicholson GM (2005) Neuroprotectant effects of iso-osmolar D-mannitol to prevent Pacific ciguatoxin-1 induced alterations in neuronal excitability: a comparison with other osmotic agents and free radical scavengers. Neuropharmacology 49, 669-686.

47. Kubista H, Mafra RA, Chong Y, Nicholson GM, Beirao PS, Cruz JS, Boehm S, Nentwig W \& Kuhn-Nentwig L (2007) CSTX-1, a toxin from the venom of the hunting spider Cupiennius salei, is a selective blocker of L-type calcium channels in mammalian neurons. Neuropharmacology 51, 1650-1662.

48. Nicholson GM, Willow M, Howden MEH \& Narahashi T (1994) Modification of sodium channel gating and kinetics by versutoxin from the Australian funnel-web spider Hadronyche versuta. Eur J Physiol 428, 400-409.

49. Zhang XF, Gopalakrishnan M \& Shieh CC (2003) Modulation of action potential firing by iberiotoxin and NS1619 in rat dorsal root ganglion neurons. Neuroscience 122, 1003-1011. 


\section{FIGURE LEGENDS}

Figure 1: Structure of the J-ACTX-Hv1c and comparison with other BK $\mathrm{BK}_{\mathrm{Ca}}$ blockers. (A) Primary structure of J-ACTX-1 family members. Identities are boxed in yellow. Green lines above the sequences represent the disulfide bonding pattern, while the arrowheads below highlight the pharmacophore (red) and proposed water-excluding gasket (pink) residues of JACTX-Hv1c. (B) Comparison of the primary structure of J-ACTX-Hv1c with known BK $\left(\mathrm{K}_{\mathrm{Ca}} 1 . \mathrm{x}\right)$ and $\mathrm{SK}_{\mathrm{Ca}}\left(\mathrm{K}_{\mathrm{Ca}} 2 . \mathrm{x}\right)$ channel blockers. Only toxins with nanomolar affinity for $\mathrm{K}_{\mathrm{Ca}}$ channels are included. Toxins listed above the BmBKTx1 sequence are $\mathrm{BK}_{\mathrm{Ca}}$ channel blockers while those below are SK $\mathrm{Ca}_{\text {a }}$ channel blockers. (C) Schematic of the structure of J-ACTX-Hv1c (PDB code 1DL0) highlighting the sidechains of the key pharmacophore residues (green) as well as those proposed to serve as a water-excluding "gasket" (see text for details). Disulfide bonds and $\beta$ strands are shown in red and cyan, respectively. (D and E) Surface representation of JACTX-Hv1c (D) and ChTx (E) highlighting the primary pharmacophore residues. In the case of ChTx ( $\alpha$-KTx 1.1), six of the eight residues crucial for activity on $\mathrm{BK}_{\mathrm{Ca}}$ channels are located on the $\beta$ strands. Pharmacophore and gasket residues are shown in green and yellow, respectively. (F) Overlay of the structure of J-ACTX-Hv1c (red) and ChTx (PDB code 2CRD, blue). (G) Stereoview of an overlay of the functional dyad of ChTx (green sidechains) with the "pseudodyad" of J-ACTX-Hv1c (red sidechains). Only the backbone of J-ACTX-Hv1c is shown for the sake of clarity.

Figure 2: Effect of J-ACTX-Hv1c on voltage-activated ion channels in cockroach neurons. (A and B) Superimposed current traces showing typical lack of effect of $1 \mu \mathrm{M}$ J-ACTX-Hv1c on $I_{\mathrm{Ca}}(\mathbf{A})$ and $I_{\mathrm{Na}}(\mathbf{B})$. (C) Inhibition of macroscopic $I_{\mathrm{K}}$ by $1 \mu \mathrm{M}$ J-ACTX-Hv1c. (D) Typical block 
of $I_{\mathrm{K}(\mathrm{Ca})}$ by increasing concentrations of ChTx (in $\mathrm{nM}$ ). Subsequent addition of TEA in the presence of $30 \mathrm{nM}$ ChTx abolished remaining current, thus confirming that currents were carried by $K_{V}$ channels. Data were recorded from the same cell. (E) Dose-response curve for ChTx inhibition of $I_{\mathrm{K}(\mathrm{Ca})}$ recorded at the end of the pulse, in the presence of $1 \mathrm{mM} \mathrm{Cd}^{2+}(n=5)$. (F and G) Typical effects of $1 \mu \mathrm{M}$ J-ACTX-Hv1c on $I_{\mathrm{K}(\mathrm{DR})}(\mathbf{F})$ and $I_{\mathrm{K}(\mathrm{A})}(\mathbf{G})$. Superimposed $I_{\mathrm{K}(\mathrm{A})}$ were obtained by current subtraction routines following prepulse potentials of -120 and $-40 \mathrm{mV}$ shown in the inset (see Methods). (H) Current subtraction routine employed to isolate $I_{\mathrm{K}(\mathrm{Ca})}$ (see Methods). Currents in panels $\mathbf{C}, \mathbf{D}, \mathbf{F}$ and $\mathbf{H}$ were elicited by the test pulse protocol shown in the inset of panel $\mathbf{F}$.

Figure 3: $J$-ACTX-Hv1c blocks $K_{\mathrm{Ca}}$ channels in cockroach DUM neurons. (A) Typical effects of $3 \mathrm{nM}$ J-ACTX-Hv1c on $I_{\mathrm{K}(\mathrm{Ca})}$ showing partial reversibility. (B) Typical effect of $1 \mu \mathrm{M}$ J-ACTX-Hv1c on rat DRG neuron macroscopic $I_{\mathrm{K}}$. (C) J-ACTX-Hv1c $(1 \mu \mathrm{M})$ failed to inhibit rat DRG neuron $I_{\mathrm{K}(\mathrm{Ca})}$ isolated by subtraction of the current remaining following addition of $100 \mathrm{nM}$ ChTx and $1 \mathrm{mM} \mathrm{Cd}^{2+}$ shown in panel B. (D) Dose-response curve showing inhibition of $I_{\mathrm{K}(\mathrm{Ca})}$ by J-ACTX-Hv1c in the presence of $1 \mathrm{mM} \mathrm{Cd}^{2+}(n=3$ at $1 \mu \mathrm{M}$ and $n=5$ at all other concentrations). Currents in panels A-D were elicited by the test-pulse protocol shown in the inset of panel A. (E and F) J-ACTX-Hv1c and ChTx share the same target in cockroach DUM neurons. (E) Addition of $1 \mu \mathrm{M} \mathrm{J-ACTX-Hv1c} \mathrm{fails} \mathrm{to} \mathrm{further} \mathrm{inhibit} I_{\mathrm{K}}$ currents blocked by perfusion with $30 \mathrm{nM}$ ChTx and $1 \mathrm{mM} \mathrm{Cd}^{2+}(n=5)$. (F) In the complementary experiment, addition of $30 \mathrm{nM}$ ChTx and $1 \mathrm{mM} \mathrm{Ca}^{2+}$ fails to further inhibit $I_{\mathrm{K}}$ currents blocked by perfusion with $1 \mu \mathrm{M}$ J-ACTX-Hv1c $(n=5)$. In both $\mathbf{E}$ and $\mathbf{F}$ currents were recorded in the presence of 4AP to block $I_{\mathrm{K}(\mathrm{A})}$. 
Figure 4: Effects of J-ACTX-Hv1c on voltage-dependence of $\mathrm{K}_{\mathrm{Ca}}$ channel activation in cockroach DUM neurons. (A and B) Typical families of $I_{\mathrm{K}(\mathrm{Ca})}$ were elicited by $10-\mathrm{mV}$ steps to $+40 \mathrm{mV}$ before (A) and after (B) the addition of $3 \mathrm{nM} \mathrm{J-ACTX-Hv1c.} \mathrm{(C-D)} I / V$ curves for fasttransient (C) and late-sustained (D) $I_{\mathrm{K}(\mathrm{Ca})}$ for controls (closed symbols), after $3 \mathrm{nM} \mathrm{J}$-ACTXHv1c (open symbols), and following prolonged washout with toxin-free solution (gray symbols) $(n=5)$. Families of currents were elicited by the test pulse protocol shown in the inset of panel $\mathbf{B}$.

Figure 5: Dose-dependent inhibition of Slo currents by J-ACTX-Hv1c (A and B) Typical effects of J-ACTX-Hv1c on pSlo at $300 \mathrm{nM}(\mathbf{A})$, and $m S l o$ at $3 \mu \mathrm{M}$ (B). (C) Dose-response curve for J-ACTX-Hv1c inhibition of Slo currents ( $\mathrm{IC}_{50}=240 \mathrm{nM}, n=6$ ). For $m$ Slo currents, the $\mathrm{IC}_{50}$ was $>9.7 \mu \mathrm{M}(n=4)$. Currents in panels $\mathbf{A}-\mathbf{C}$ were elicited by the upper test pulse protocol shown between panels A and B. (D) Timecourse of block of pSlo currents by $300 \mathrm{nM}$ J-ACTXHv1c and washout in toxin-free solution $(n=5)$. ( $(\mathbf{F}$ and $\mathbf{F})$ Typical families of $I_{\mathrm{K}(\mathrm{Ca})}$ were elicited by $10-\mathrm{mV}$ steps from -90 to $+80 \mathrm{mV}$ before (E) and after (F) addition of $300 \mathrm{nM} \mathrm{J-ACTX-Hv1c.}$ Families of currents were elicited by the test-pulse protocol shown between panels $\mathbf{E}$ and $\mathbf{F}$. (G) $I / V$ curves for late $p S l o$ currents. Data corresponds to controls (closed symbols), after addition of $3 \mathrm{nM}$ J-ACTX-Hv1c (open symbols), and following washout with toxin-free solution (gray symbols) $(n=6)$. (H) Voltage-dependence of the fractional block of pSlo currents by $300 \mathrm{nM}$ J-ACTX-Hv1c $(n=6)$.

Figure 6: Effect of J-ACTX-Hv1c mutants on cockroach DUM neuron $I_{K(C a)}$. (A-D) Typical 
effects of (A) $10 \mathrm{nM} \mathrm{R8H,} \mathrm{(B)} 300$ nM R8K, (C) $300 \mathrm{nM}$ Y31F and (D) $30 \mathrm{nM}$ V29A mutants on $I_{\mathrm{K}(\mathrm{Ca})}$. Calibration bars represent $5 \mathrm{nA}$ and $25 \mathrm{~ms}$. (E-G) Dose-response curves for inhibition of peak $I_{\mathrm{K}(\mathrm{Ca})}$ by $\operatorname{Arg}^{8}(\mathbf{E}), \operatorname{Tyr}^{31}(\mathbf{F})$, and $\mathrm{Val}^{29}$ and $\operatorname{Pro}^{9}(\mathbf{G})$ mutants $(n=3-4)$. (H) Comparison of fold-reduction in DUM neuron $I_{\mathrm{K}(\mathrm{Ca})} \mathrm{IC}_{50}$ (left $y$-axis, light bars) and house fly $\mathrm{LD}_{50}$ (right $y$-axis, dark bars). For comparison, data for the fold-reduction in house fly $\mathrm{LD}_{50}$ for R8A, R8E, P9A, Y31F and Y31A mutants are included [4]. * Mutant Y31A (gray symbols in panel F) has an estimated $\mathrm{IC}_{50}$ value $\geq 10 \mu \mathrm{M}$.

Figure 7: Alignment of the pore region of vertebrate and invertebrate Slo channels. This alignment is restricted to the pore region located between transmembrane segments S5 and S6. Sequences are from insects (Periplaneta americana, p; Anopheles gambiae, a; Apis mellifera, Am; Tribolium castaneum, Tc; Manduca sexta, Ms; Drosophila melanogastor, $d$; and D. pseudoobscura, $D p$ ), vertebrates (chicken, $c$; mouse, $m$; rat, $r$; human, $h$; rabbit, $R b$; bovine, $b$; Canis familiaris, Cf; and Xenopus laevis, x), marine invertebrates (Cancer borealis, Cb; and Aplysia californica, $A c)$ and Caenorhabditis elegans (Ce). Identical residues are boxed in gray while conservative substitutions are in gray italic text. Arrowheads denote residues important for ChTx binding (see text for details). 
TABLE 1: Phyletic selectivity of J-ACTX-Hv1c and ChTx

\begin{tabular}{|c|c|c|c|}
\hline \multirow{2}{*}{\multicolumn{2}{|c|}{$\mathrm{BK}_{\mathrm{Ca}}$ channel }} & \multicolumn{2}{|c|}{$\mathrm{IC}_{50}(\mathrm{nM})$} \\
\hline & & \multirow{2}{*}{$\begin{array}{c}\text { J-ACTX-Hv1c } \\
2.3 \\
\end{array}$} & \multirow{2}{*}{$\begin{array}{c}\operatorname{ChTx}^{a} \\
1.9^{*}, 1.4^{\mathrm{b}}\end{array}$} \\
\hline Inunthnot & Native DUM neuron $\mathrm{BK}_{\mathrm{Ca}}$ & & \\
\hline mverteorate & pSlo & 240 & $158^{\mathrm{b}}$ \\
\hline \multirow{3}{*}{ Vertebrate } & Native rat DRG neuron $\mathrm{BK}_{\mathrm{Ca}}$ & $>1000$ & $<100^{\mathrm{a}}$ \\
\hline & hSlo & N.D. & $36^{c}$ \\
\hline & mSlo & 9776 & $7.4^{\mathrm{c}}$ \\
\hline \multicolumn{2}{|c|}{ 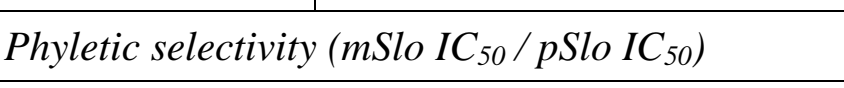 } & 41 & 0.047 \\
\hline
\end{tabular}

ChTx data from ${ }^{\mathrm{a} S}$ Scholz et al. (1998), ${ }^{\mathrm{b}}$ Derst et al. (2003), ${ }^{\mathrm{C}}$ Myers et al. (2000), and *present study.

N.D., not determined. 